\title{
Cardiac enzymes in patients undergoing Caesarean section
}

Robert M. Ross MD, Thomas Baker MS

Some of the changes reported in the ECG of parturients undergoing Caesarean section are suggestive of myocardial ischaemia. This study determined serum $C K$ total and the isoenzyme $C K \cdot M B$ levels in 21 patients during and after Caesarean section under epidural anaesthesia. Twenty patients complained of chest pain, discomfort and pressure, while 12 had ST segmental depression. Although the total $C K$ activity in ten patients was elevated, $C K-M B$ activity in all patients was negative. The electrocardiographic changes were rate-related and occurred at the time pressure was placed upon the upper abdomen and lower thoracic cage by the surgeon to facilitate Caesarean delivery. The data from this study demonstrate that no myocardial injury as measured by $C K-M B$ activity occurs in parturients undergoing Caesarean delivery despite the complaint of chest pain, discomfort and pressure, and ST changes in the ECG.

Certains changements observés sur l'ECG de parturientes soumises à une césarienne suggèrent liuschémie myocardique. Ce travail évalue les niveaux de la $C K$ sérique totale et de l'enzyme $C P K-M B$ chez 21 patientes pendant et après la césarienne sous anesthésie épidurale. Vingt patientes se sont plaintes de douleurs thoraciques, de sensation dinconfort et de serrement, alors que 12 présentaient une dépression du segment ST. Bien que l'activité totale de la CK chez six patientes ait été élevée. l'activité de la CPK-MB était négative chez toutes les patientes. Les changements à l'ECG étaient reliés à la fréquence et sont survenus au moment où la pression était appliquée sur l'abdomen supérieur et sur la cage thoracique inférieure par le chirurgien pour faciliter l'extraction. Les données de cette étude prowvent qu'il y a absence de lésion myocardique comme le démontre l'activité de la CPK-MB chez des parturientes soumises à l'ex-

\section{Key words}

ANAESTHESIA: obstetric;

COMPLICATIONS: myocardial ischaemia;

HEART: ischaemia;

MONITORING: electrocardiography.

From the Department of Anesthesiology, Monmouth Medical Center, 300 Second Avenue, Long Branch, NJ 07740, U.S.A.

Address correspondence to: Dr. Robert M. Ross,

Department of Anesthesiology, Monmouth Medical Center, 300 Second Avenue, Long Branch, NJ 07740, U.S.A.

Accepted for publication 26th August, 1994. traction par césarienne malgré la description de douleur thoracique, de sensation dinconfort et de serrement, et l'observation de changements du segment ST à l'ECG.

A common complaint of parturients having regional anaesthesia for Caesarean delivery is shortness of breath and chest pressure or pain. These complaints are similar to those made by symptomatic cardiac patients with myocardial ischaemia. Palmer et al. ${ }^{1}$ found that ECG changes occurred in $47 \%$ of parturients. In fact, these investigators speculated that myocardial ischaemia was the likely cause of both the ECG changes and the chest pain that develops in these patients. Mathew et al. ${ }^{2}$ found $29 \%$ of parturients undergoing Caesarean delivery with epidural anaesthesia demonstrated ST segment depression and concluded that episodes of ST depression were not an artifact of Caesarean section. In another study, 16 of 25 patients during elective Caesarean delivery had ST segment depression. In these patients, echocardiograms showed normal cardiac wall motion during the episodes of ST depression. ${ }^{3}$ These authors concluded that ST segment depression during Caesarean section under epidural anaesthesia was not the result of myocardial ischaemia. However, a measurement of the activity of the MB isoenzyme of creatine kinase (CK) in plasma is the method of choice for the diagnosis or exclusion of acute myocardial damage. ${ }^{4}$ In the present study, the activities of $\mathrm{CK}$ and $\mathrm{CK}-\mathrm{MB}$ were determined in parturients during and after Caesarean delivery.

\section{Methods}

The approval of the Institutional Research Review Board was secured, and informed consent was obtained from 24 patients of ASA physical status Class 1 or 2 undergoing elective Caesarean delivery. Patients with coexisting disease which could influence the outcome of this investigation were excluded. The anaesthesia for all patients was continuous lumbar epidural.

All patients were prehydrated with $1500 \mathrm{ml}$ lactated Ringer's solution. A 20-gauge closed-tip catheter (via an 18-gauge Tuohy needle) was placed at the $\mathrm{L}_{2}-\mathrm{L}_{3}$ or $\mathrm{L}_{3}$ $\mathrm{L}_{4}$ interspace. Bupivacaine $0.5 \%$ was administered to one patient with a history of chronic hypertension. The rest 
TABLE I Patient population demographic characteristic (mean values \pm SD)

\begin{tabular}{lllll}
\hline & $\begin{array}{l}\text { Sample } \\
\text { size }\end{array}$ & $\begin{array}{l}\text { Age } \\
y r\end{array}$ & $\begin{array}{l}\text { Weight } \\
K g\end{array}$ & $\begin{array}{l}\text { Height } \\
\mathrm{cm}\end{array}$ \\
\hline A: All patients & 24 & $29.8 \pm 4.1$ & $89.8 \pm 17.8$ & $164.0 \pm 6.6$ \\
B: With chest pain & 20 & $29.1 \pm 3.9^{a}$ & $89.4 \pm 18.3$ & $163.1 \pm 6.1$ \\
C: No chest pain & 4 & $33.5 \pm 2.9$ & $91.4 \pm 18.4$ & $168.9 \pm 7.3$ \\
D: With ECG changes & 12 & $28.0 \pm 2.6^{b}$ & $81.3 \pm 13.0^{c}$ & $165.5 \pm 6.4$ \\
E: No ECG changes & 12 & $31.7 \pm 4.5$ & $98.2 \pm 18.4$ & $162.6 \pm 6.7$ \\
\hline
\end{tabular}

${ }^{a} P \leq 0.05$ vs patients without chest pain.

${ }^{b} P \leq 0.05$ vs patients without ECG changes.

${ }^{c} P \leq 0.05$ vs patients without ECG changes.

of the subjects were given lidocaine $2 \%$ with epinephrine $(1 / 200,000)$. Incremental doses of the local anaesthetic were administered to achieve a $T_{4}$ sensory block with the mean total dose ( $\pm S D$ ) being $402 \pm 27 \mathrm{mg}$, range $360-440 \mathrm{mg}$. No clinical signs of intravenous absorption of epinephrine or local anaesthetic were observed.

Maternal systolic, diastolic and mean arterial blood pressure were monitored every three minutes throughout the procedure with the heart rate and heart rhythm being monitored continuously using the modified $V_{5}$ lead placement scheme and recording with lead 2 of the Siemens 400 System. In the modified $V_{5}$ lead placement scheme, the left arm lead was placed on the anterior axillary line in the fifth intercostal space, and the right arm lead was placed over the manubrium sterni. This configuration was more sensitive in detecting mycardial ischaemia. Ischaemic ECG changes were defined as a reversible ST depression from the baseline $\geq 1 \mathrm{~mm}$ or a ST elevation $\geq 2 \mathrm{~mm}$ at the J-point lasting for at least one minute. The ECG recordings were obtained with an annotating strip recorder.

Oxygen saturation was monitored with a Nellcor pulse oximeter. After epidural placement, oxygen (3-4 $\mathrm{L} \cdot \mathrm{min}^{-1}$ ) was administered via a nasal cannula. Oxytocin (20 units $\cdot \mathrm{L}^{-1}$ ) was added to the $i v$ solution after delivery of the placenta.

Blood samples were drawn from an arm vein into 10 $\mathrm{ml}$ tubes before the beginning of the surgical procedure for control, at delivery, and at 4, 12, and $24 \mathrm{hr}$ postpartum. The samples were stored at $-20^{\circ} \mathrm{C}$. For each patient, the total creatine kinase (CK) activity and CKMB isoenzyme activity were determined simultaneously on the preoperative and postoperative samples on the day the samples were received in the laboratory. The isoenzyme CK-MB is one of three isoenzymes (CK-BB, CK$\mathrm{MB}, \mathrm{CK}-\mathrm{MM}$ ) and is specifically related to myocardial muscle damage. Creatine kinase (CK) and isoenzymes computations were determined by column chromatography. ${ }^{5}$ This was then followed by immunoassay (Roche) for confirmation of the CK-MB isoenzyme determined by column chromatography. ${ }^{6}$

The Wilcoxon Signed Rank and Mann-Whitney U tests were used to analyze data of independent groups at same time periods. ANOVA with a Neuman-Keuls test was used to compare data of the same group at different time periods. The significance of negative results was determined using a negative inference test. ${ }^{5}$ A $P$ value of $\leq 0.05$ was considered significant.

\section{Results}

The mean values ( $\pm S D$ ) and (ranges) for the age, weight and height of the participating patients were $29.8 \pm 4.1$ (25-38) yr; $89.8 \pm 18.3(62.7-124.1) \mathrm{kg}$; and $164.0 \pm$ $6.6(154.9-175.3) \mathrm{cm}$; respectively (Table I). Twenty of the participating patients experienced chest pain; 12 had ST segment changes. Among these subgroups, the demographic characteristics were similar (Table I). Interestingly, parturients who experienced chest pain were younger than those who had no chest pain (Table I). A similar difference in age was found in patients with ST segment depression. Also, patients with ECG changes weighed less. While these differences were statistically significant, they were not clinically important.

The mean 24 hour CK value $\left(103.8 \mathrm{U} \cdot \mathrm{L}^{-1}\right.$ of all subjects was different from those obtained at the other four times: control, delivery, $4 \mathrm{hr}$ and $12 \mathrm{hr}$ (Table II). In addition, the control $C K$ value of $47.5 \mathrm{U} \cdot \mathrm{L}^{-1}$ was different from the values of four hours, $78.5 \mathrm{U} \cdot \mathrm{L}^{-1}$, and $12 \mathrm{hr}, 75.0 \mathrm{U} \cdot \mathrm{L}^{-1}$. The average $\mathrm{CK}$ level of samples taken before the start of surgery fell well within the normal range. At the time of delivery, the average heart rate of 121 beats per minute (bpm) was greater than the control rate of $96 \mathrm{bpm}(P \leq 0.05)$, but the average systolic blood pressure $(121.8 \mathrm{mmHg})$ was less than the control of $129.6 \mathrm{mmHg}(P \leq 0.05)$, while the average diastolic pressures were unchanged.

At delivery, 20 of the $24(83.3 \%)$ patients complained of chest discomfort, pressure or pain. Their CK values 
TABLE II A haemodynamic comparison, CK and CK-MB levels (mean values \pm SEM)

\begin{tabular}{lccccc}
\hline & All parients & Chest pain & No pain & ECG changes & No changes \\
\hline C-HR & $95.7 \pm 2.6$ & $96.0 \pm 2.9$ & $94.0 \pm 7.5$ & $97.7 \pm 3.8$ & $93.7 \pm 3.8$ \\
C-SP & $129.6 \pm 2.2$ & $130.3 \pm 2.6$ & $126.0 \pm 2.3$ & $128.7 \pm 2.8$ & $130.5 \pm 3.5$ \\
C-Dp & $71.2 \pm 2.2$ & $70.4 \pm 2.6$ & $75.0 \pm 3.5$ & $70.7 \pm 4.0$ & $71.7 \pm 2.2$ \\
C-CK & $47.5 \pm 7.9^{b}$ & $51.1 \pm 9.3$ & $29.5 \pm 1.4$ & $34.5 \pm 2.6$ & $60.5 \pm 15.0$ \\
C-MB & 0 & 0 & 0 & 0 & 0 \\
D-HR & $120.9 \pm 4.2^{r}$ & $121.4 \pm 4.9$ & $118.5 \pm 6.6$ & $138.3 \pm 2.1^{h}$ & $103.5 \pm 3.8$ \\
D-SP & $121.8 \pm 3.0^{d}$ & $123.8 \pm 3.2$ & $11.5 \pm 6.1$ & $130.2 \pm 4.2^{i}$ & $113.3 \pm 2.6$ \\
D-Dp & $70.7 \pm 2.2$ & $68.3 \pm 2.2^{f}$ & $82.5 \pm 4.9$ & $75.0 \pm 1.4$ & $66.3 \pm 3.9$ \\
D-CK & $57.7 \pm 7.6$ & $61.1 \pm 8.8$ & $40.5 \pm 6.1$ & $41.5 \pm 3.4$ & $73.8 \pm 13.4$ \\
D-MB & 0 & 0 & 0 & 0 & 0 \\
4Hr-CK & $78.5 \pm 8.4$ & $80.2 \pm 9.3$ & $70.0 \pm 9.3$ & $65.0 \pm 8.7$ & $92.0 \pm 13.8$ \\
4Hr-MB & 0 & 0 & 0 & 0 & 0 \\
12Hr-CK & $75.0 \pm 7.2$ & $78.3 \pm 7.8$ & $58.5 \pm 17.6$ & $74.7 \pm 11.9$ & $75.3 \pm 8.6$ \\
12Hr-MB & 0 & 0 & 0 & 0 & 0 \\
24Hr-CK & $103.8 \pm 14.4^{a}$ & $108.6 \pm 16.4^{e}$ & $80.0 \pm 29.4$ & $90.0 \pm 18.0^{\circ}$ & $117.7 \pm 22.7$ \\
24Hr-MB & 0 & 0 & 0 & 0 & 0 \\
\hline
\end{tabular}

$\mathrm{C}=$ control; $\mathrm{D}=$ delivery; $\mathrm{HR}=$ heart rate beats $\cdot \mathrm{min}^{-1} ; \mathrm{SP}=$ systolic pressure $\mathrm{mm}$ of $\mathrm{Hg} ; \mathrm{DP}=$ diastolic pressure $\mathrm{mm}$ of $\mathrm{Hg} ; \mathrm{CK}=\mathrm{creatine}$ kinase $\mathrm{U} \cdot \mathrm{L}^{-1} ; \mathrm{MB}=$ specific myocardial muscle isoenzyme of $\mathrm{CK} \mathrm{U} \cdot \mathrm{L}^{-1}$.

${ }^{a} P \leq 0.05$ vs $C K$ values at other four times.

${ }^{b} P \leq 0.05$ vs CK values at 4 and $12 \mathrm{hr}$.

$" P \leq 0.05$ vs control heart rate.

${ }^{d} P \leq 0.05$ vs control systolic pressure.

e $P \leq 0.05$ vs $C K$ values of other four times.

$f_{P} \leq 0.05$ vs delivery diastolic pressure of no chest pain.

${ }_{R} P \leq 0.05$ vs delivery $C K$ values of control and at delivery.

${ }^{h} P \leq 0.05$ vs delivery heart rate with no ECG changes.

i $P \leq 0.05$ vs delivery systolic pressure with no ECG changes.

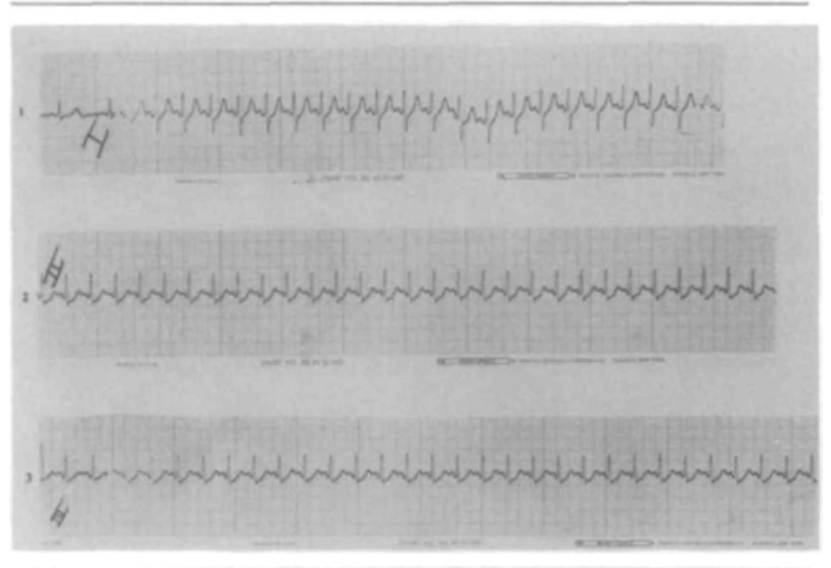

FIGURE Examples of ECG ST depression at the time of delivery in three different patients.

were greater at $24 \mathrm{hr}\left(108.6 \mathrm{U} \cdot \mathrm{L}^{-1}\right)$ than at the other four test periods, but among the four test times of control, delivery, $4 \mathrm{hr}$ and $12 \mathrm{hr}$, there were significant differences in CK values. At none of the test times was any CK$\mathrm{MB}$ activity found. The average heart rate $(121.4 \mathrm{bpm})$ of these 20 patients at delivery was not different from the rate $(118.5 \mathrm{bpm})$ of the patients who had no chest pain at delivery. There were also no differences in the average systolic blood pressures between these patients at the time of delivery. However, the mean diastolic blood pressure in these two groups was different at delivery; those experiencing chest pain having the lower pressure (68.3 $\mathrm{mm}$ vs $82.5 \mathrm{~mm}, P \leq 0.05$ ).

At the time of delivery, 12 of the $24(50 \%)$ patients showed ST segmental depression (Figure). The pattern of these 12 patients' $\mathrm{CK}$ values was similar to that in the chest pain group, but the 24 hour value was different from the values at control and delivery $(P \leq 0.05)$. In none of these patients was any CK-MB levels. Both the heart rate $(138.3 \mathrm{bpm})$ and the systolic blood pressure $(113.3 \mathrm{~mm})$ of these patients at delivery were greater than heart rate $(103.5 \mathrm{bpm})$ and systolic pressure $(103.2 \mathrm{~mm})$ of the patients who had no ST segment depression $(P \leq 0.05)$.

Of the 12 patients with ST segment changes, ten also had chest pain. The blood pressures and heart rates of these ten patients were compared with those patients who had no chest pain and no ST depression (Table III). Of the 24 patients, there were only two patients in this latter group. They had the lower systolic pressure (131.8 vs $107.0 \mathrm{mmHg}$ ) and heart rate (140.0 vs $106.0 \mathrm{bpm})$ while their diastolic pressure (75.2 vs $92.0 \mathrm{mmHg}$ ) was higher. Since there were only two patients in the no chest pain and no ST depression group, the confidence levels 
TABLE IIIA Comparison of mean ( \pm SEM) blood pressures and heart rates: patients who had both ECG changes and chest pain vs patients who had no ECG changes and no chest pain

\begin{tabular}{llll}
\hline Group & $\begin{array}{l}\text { Systolic } \\
\text { pressure } \\
\mathrm{mmHg}\end{array}$ & $\begin{array}{l}\text { Diastolic } \\
\text { pressure } \\
\mathrm{mmHg}\end{array}$ & $\begin{array}{l}\text { Heart } \\
\text { rate } \\
b p m\end{array}$ \\
\hline Both pain and ST changes $n=10$ & $131.8 \pm 5.0$ & $75.2 \pm 1.8$ & $140.0 \pm 2.6$ \\
No pain and no ST changes $n=2$ & $107.0 \pm 6.0$ & $92.0 \pm 1.0$ & $106.0 \pm 1.0$ \\
\hline
\end{tabular}

TABLE IIIB Comparison of 95\% confidence levels of blood pressures and heart rates: patients who had both ECG changes and chest pain vs patients who had no ECG changes and no chest pain

\begin{tabular}{llll}
\hline & $\begin{array}{l}\text { Systolic } \\
\text { pressure } \\
m m H g\end{array}$ & $\begin{array}{l}\text { Diastolic } \\
\text { pressure } \\
m m H g\end{array}$ & $\begin{array}{l}\text { Heart } \\
\text { rate } \\
b p m\end{array}$ \\
\hline Group & $\begin{array}{l}122.7 \text { to } 141.9 \\
69.1 \text { to } 144.9\end{array}$ & $\begin{array}{l}72.0 \text { to } 78.4^{a} \\
85.7 \text { to } 98.3\end{array}$ & $\begin{array}{c}136.0 \text { to } 144.0^{b} \\
97.7 \text { to } 112.3\end{array}$ \\
\hline Noth pain and ST changes $n=10$ & and no ST changes $n=2$ &
\end{tabular}

$\mathrm{df}=$ degree of freedom.

${ }^{\circ} P \leq 0.05$ vs no pain and no ST changes diastolic pressure group.

${ }^{b} P \leq 0.05$ vs no pain and no ST changes heart rate group.

of the systolic pressure, diastolic pressure and heart rate were calculated (Table IIIB). The confidence level was inferred from the mean, standard error of the mean and the degree of freedom. Since the $P$ value was 0.05 , the confidence level was $95 \%$. It predicted the range within which the true means of the entire population (not the sample population) would fall with a probability of being correct 19 out of 20 . The confidence levels for the systolic pressures overlapped, but they were significantly separated for both the diastolic pressures and heart rates.

\section{Discussion}

Although 20 of these patients complained of chest discomfort, pain or pressure and 12 had ST depression, none had any CK-MB activity up to $24 \mathrm{hr}$ after delivery. The CK-MB levels are found in blood three to four hours after infarction and disappear $36 \mathrm{hr}$ later. Any increase in CK-MB levels would have been detected in the blood samples taken at 4, 12 and $24 \mathrm{hr}$. From analyzing these data using the inference test based upon negative results, ${ }^{7}$ the results indicated that myocardial injury, as measured by CK-MB activity, was not the cause of these complaints. Further, a study of cardiac wall motion in parturients during ST segment depression demonstrated normal function. ${ }^{3}$ Thus, the findings of studies utilizing different techniques support the conclusion that there is no ischaemic injury to cardiac tissue in parturients undergoing Caesarean section. The group of patients who had chest pain did have a lower diastolic blood pressure than the group that had no chest pain. The perfusion of cardiac tissue is dependent upon diastolic pressure. Perhaps these patients may be sensitive to lower cardiac per- fusion flow. Interestingly, the patients who had neither chest pain nor ST segment depression had the highest diastolic blood pressure at delivery. Another probable source of the chest pain and discomfort is the fundal pressure placed upon the upper abdomen and lower thoracic cage by the surgeon to facilitate delivery.

At the time of delivery, the systolic blood pressure of the patients who had ST segment depression at delivery was greater than that of patients who did not have any ST depression. This acute volume depletion together with the fundal pressure applied by the surgeon was the most likely cause of the observed tachycardia and the rate related ST depression of the electrocardiogram. The evidence that the ST depression was rate-related is based upon the data that those patients who did not develop ST depression at delivery had a heart rate which was lower than in subjects who did have ST depression, and as the heart rate returned to the baseline, the ST depression quickly disappeared. Again, the patients who had neither chest pain nor ST segment depression had the lowest heart rate at delivery. The elevated CK levels found at the various times after surgery reflected muscle tissue damage. In none of the patients was any CK-MB activity found. The lack of this activity indicated that no cardiac ischaemia occurred.

Chest pain, discomfort and pressure, and shortness of breath are not uncommon subjective complaints of patients undergoing Caesarean delivery under regional anaesthesia. Palmer et al. ${ }^{1}$ described ECG changes suggestive of myocardial ischaemia and speculated that, indeed, it was the likely cause of the changes in the ECG and the symptoms of chest pain and dyspnoea which 
these patients exhibited. Furthermore, Malinow et al. ${ }^{8}$ correlated patients' complaints of chest pain with precordial Doppler evidence of venous air emboli.

No one, to our knowledge, has investigated the subjective complaints of chest discomfort with the measurements of CK level activity as an indicator of myocardial damage. In addition, no one has addressed the issue of silent myocardial damage which could be attributed to the direct effect of myocardial contusion secondary to aggressive fundal pressure during difficult Caesarean delivery.

It is concluded that the ST depression which can be accompanied with chest pain is not associated with myocardial tissue damage in parturients undergoing elective Caesarean section as measured by $\mathrm{CK}-\mathrm{MB}$ levels. In none of the patients with ST depression was the CK-MB levels elevated. Those patients who experienced chest pain along with the ST depression had significantly more tachycardia and greater systolic and lower diastolic blood pressure than those patients who did not have any ST depression and no chest pain.

\section{Acknowledgement}

The authors wish to thank B.M. Mitruka, Ph.D., M.D., Department of Pathology of Monmouth Medical Center for conducting the $\mathrm{CK}$ and $\mathrm{CK}-\mathrm{MB}$ tests.

\section{References}

1 Palmer CM, Norris MC, Giudici MC, Leighton BL, DeSimone $C A$. Incidence of electrocardiographic changes during cesarean delivery under regional anesthesia. Anesth Analg 1990; 70: 36-43.

2 Mathew JP, Fleisher LA, Rinehouse JA, et al. ST segment depression during labour and delivery. Anesthesiology 1992; 77: 635-41.

3 McLintic AJ, Pringle SD, Lilley S, Houston AB, Thornburn $J$. Electrocardiographic changes during cesarean section under regional anesthesia. Anesth Analg 1992; 74: 51-6.

4 Weinberger I, Fuchs J, Rotenberg Z, Davidson E, Harel D, Agmon J. Changes in creatine kinase activity in the course of acute myocardial infarction. Clin Chem 1989; 35: 414-6.

5 Tsung $S H$. Several conditions causing elevation of serum CK-MB and CK-BB. Am J Clin Pathol 1981; 75: 711-5.

6 Eisenberg PR, Shaw D, Schaab C, Jaffe AS. Concordance of creatine kinase-MB activity and mass. Clin Chem 1989; 35: 440-3.

7 Grayzel J. A statistic for inferences is based upon negative results (Letter). Anesthesiology 1989; 71: 320-1.

8 Malinow AM, Naulty JS, Hunt CO, Datta S, Osterheimer $G W$. Precordial ultrasonic monitoring during cesarean delivery. Anesthesiology 1987; 66: 816-9. 